\title{
Pesquisando ao ensinar: prática no laboratório didático analisa o comportamento verbal sob contingências de reforçamento positivo e negativo ${ }^{1}$
}

\author{
Researching while teaching: laboratory activity \\ analyzes verbal behavior under contingencies of \\ positive and negative reinforcement
}

\author{
Gerson Yukio TOMANARI ${ }^{2}$ \\ Anamélia Araújo de CARVALHO ${ }^{3}$ \\ Zorilda Santos GÓES \\ Sidnei Barbosa de LIRA ${ }^{3}$ \\ Anderson Cesar Veloso VIANA ${ }^{3}$
}

\begin{abstract}
Resumo
No contexto de ensino da análise experimental do comportamento, 53 graduandos foram expostos à tarefa informatizada de construir frases. Iniciou-se o experimento com linha de base, na ausência de contingência experimental. A seguir, os participantes, em dois diferentes grupos, podiam ganhar (vs. manter) ou manter (vs. perder) pontos, segundo contingências programadas de reforçamento positivo ou negativo, respectivamente, aplicadas ao uso de um pronome previamente selecionado, "nós" ou "ele(a)". Os resultados revelaram que, durante a linha de base, todos os seis pronomes foram utilizados em freqüências próximas ao acaso. Na condição experimental, houve um aumento acentuado no uso do pronome selecionado para reforçamento. Esse aumento foi gradual e sistemático para os sujeitos de ambos os grupos e, interessantemente, em freqüência média mais elevada sob reforçamento negativo do que positivo. Tais dados sugerem diferentes efeitos dessas duas contingências sobre o comportamento humano, avaliados em situações eticamente aceitáveis e no contexto didático que visa à formação de atitudes científicas.
\end{abstract}

Unitermos: universitário; comportamento verbal; contingências de reforço; prática de ensino.

\begin{abstract}
Fifty-three undergraduate students were exposed to the computer task of making sentences. The experiment started with baseline, in which no reinforcement was applied. During the experimental condition, subjects in different groups had the use of a specific pronoun previously selected by the experimenter under the contingencies of positive and negative reinforcement. The results described a systematic pattern among subjects towards the frequency distribution of pronouns used during the baseline. During the reinforcement condition, there was the

$\boldsymbol{\nabla} \boldsymbol{\nabla} \boldsymbol{\nabla} \boldsymbol{\nabla}$

1 O desenvolvimento do programa Verbal 1.51 e suas atualizações posteriores foram financiados pelas Pró-Reitorias de Graduação e Pós-Graduação da Universidade de São Paulo por meio do Sistema Integrado de Apoio ao Ensino (Programa SIAE, Editais 1998 e 2001).

2 Universidade de São Paulo, Instituto de Psicologia, Departamento de Psicologia Experimental. Av. Prof. Mello Moraes, n.1721, 05508-030, Butantã, São Paulo, SP, Brasil. Correspondência para/Correspondence to: G. Y. TOMANARI. E-mail: <tomanari@usp.br>.

3 Faculdade Ruy Barbosa, Curso de Psicologia. Salvador, BA, Brasil.
\end{abstract}


increase in the frequency of the pronouns under reinforcement. In the present study, the negative reinforcement contingency (vs. the positive one) resulted in greater increase in the use of the selected pronoun. These data suggest different effects of the positive and negative reinforcement contingencies on the human behavior, evaluated not only in ethical conditions, but also in the learning context that aims to establish scientific attitudes.

Uniterms: undergratuate; verbal behavior; contingencies of reinforcement; teaching activity.

O comportamento verbal, como definido por Skinner (1957), é uma classe de comportamentos que obedece aos mesmos princípios de qualquer outro operante, porém que se particulariza pela necessidade de que seja mediado por um organismo de uma mesma comunidade verbal - esteja ou não esse organismo presente no momento de ocorrência da resposta verbal (Passos, 2004).

Estudos teóricos sobre o comportamento verbal, por diversas razões, inclusive metodológicas, não têm sido acompanhados por investigações empíricas, tampouco experimentais, à altura da importância dessa área de investigação. Embora em pequena quantidade, entretanto, existem estudos na área que demonstram a relação funcional entre o comportamento verbal e suas conseqüências (Greenspoon, 1955; Krasner, 1958; Taffell, 1955; Wilson \& Verplank, 1956).

Greenspoon (1955), por exemplo, investigou a possibilidade de alterar a freqüência de uso de palavras no plural, dado o reforçamento dessas pelo experimentador. No caso, Greenspoon solicitava ao participante que dissesse uma palavra. Somente quando a palavra dita encontrava-se no plural, o experimentador imediatamente emitia uma vocalização que considerava de aprovação, reforçadora ("hã-hã"). Ao longo de tal procedimento, os resultados revelaram um aumento relativo na freqüência de uso de palavras no plural, demonstrando, portanto, a efetividade do reforçador empregado e, sobretudo, naquele contexto, a suscetibilidade do comportamento verbal às suas conseqüências, como qualquer outro operante não verbal.

Na mesma linha de investigação, Taffell (1955) propôs uma situação experimental que trazia, como um dos objetivos, investigar os efeitos de conseqüenciar diferencialmente - por meio de respostas verbais e não verbais - oralizações de pacientes de um hospital psiquiátrico. $\mathrm{O}$ experimentador apresentava cartões contendo um único verbo, abaixo do qual havia uma lista com seis pronomes ("I, We, You, He, She, They") apresentados em ordem aleatória e variável em cada cartão.
A tarefa do participante era construir uma frase para cada um dos verbos apresentados, utilizando qualquer um dos pronomes listados. Oitenta verbos formavam uma sessão; os vinte primeiros constituíam a linha de base em que não se aplicava qualquer conseqüência diferencial. A partir do vigésimo primeiro verbo, o experimentador passava a conseqüenciar todas as frases em que os participantes utilizavam os pronomes "I"ou"We". Ao final e imediatamente após a elaboração de uma frase em que houvesse sido empregado "I" ou "We", o experimentador dizia good ("bom") (grupo 1), ou acionava um piscar de luz (grupo 2), ou não liberava conseqüência alguma (grupo 3).

Os resultados do estudo de Taffel (1955) mostraram que, somente para os participantes do grupo 1 , houve aumento na freqüência de uso dos pronomes" "I" e "We" na fase de reforçamento, comparada à linha de base. Resultados semelhantes não se observaram para os sujeitos dos grupos 2 e 3, fortalecendo as evidências acerca da efetividade das conseqüências verbais aplicadas ao pronome usado pelos sujeitos na elaboração de suas frases.

Recentemente, no contexto de uma atividade didática realizada no laboratório de Análise Experimental do Comportamento, Matos, Cirino, Passos, Damiani e Frochtengarten (1995) propuseram um método de trabalho para a demonstração do controle do comportamento verbal como um operante. O método foi baseado em Taffel (1955), e encontra-se proposto detalhadamente como uma prática de laboratório em Matos eTomanari (2002).

No trabalho de Matos et al. (1995), os estudantes formaram trios; um deles atuava como sujeito experimental e dois como experimentadores. Cento e vinte verbos no infinitivo, criteriosamente selecionados pelos programadores do experimento, foram impressos em cartões e apresentados um a um ao sujeito. Em um cartão à parte, sempre à vista do sujeito, encontrava-se 
uma lista contendo, em seqüência aleatória, os seis pronomes do caso reto: "Eu", "Tu", "Ele(a)", "Nós", "Vós", "Eles(as)". A tarefa do sujeito consistia em construir frases, iniciadas por um dos pronomes mostrados, utilizando o verbo apresentado. Os vinte primeiros verbos formavam a fase de linha de base e não estavam sujeitos a qualquer reforçamento diferencial programado. $\mathrm{Na}$ fase de reforçamento, que tinha início a partir do $21^{\circ}$ verbo, a utilização de um pronome previamente selecionado pelo experimentador era acompanhada, ao final da frase, por uma verbalização de um dos experimentadores ("hã-hã","certo," "isso mesmo,",correto", entre outras). Diferentes grupos foram formados, cada qual com um único pronome selecionado para reforçamento.

Ao outro experimentador, cabia a tarefa de registrar os eventos experimentais. O trabalho de Matos et al. (1995), além de servir como uma prática de laboratório, gerou dados originais. Os autores verificaram padrões regulares na distribuição de uso dos pronomes da língua portuguesa, mesmo na ausência de reforçamento (linha de base). Em ordem crescente de utilização, foram empregados os pronomes "tu" e "vós", "nós" e "eles(as)", "ele(a)" e, finalmente, "eu". Na fase de reforçamento, tomando-se a média do grupo, verificou-se que o pronome cujo uso era reforçado alterava a hierarquia previamente estabelecida, em particular aumentando claramente a freqüência do pronome reforçado. O trabalho de Matos et al. (1995), além de contribuir metodologicamente para o estudo do comportamento verbal, no contexto de um exercício no laboratório didático, fortaleceu e ampliou as demonstrações dos efeitos de conseqüenciar diferencialmente respostas verbais.

A despeito de suas contribuições metodológicas, o estudo de Matos et al. (1995) apresenta limitações que se encontram refletidas na alta variabilidade encontrada no desempenho dos sujeitos. Pode-se verificar os efeitos do reforçamento nos dados médios dos participantes; contudo, individualmente, esses efeitos são muitas vezes ausentes ou contrários à tendência média. Muito provavelmente, tais diferenças individuais decorrem, em grande parte, das diferenças na execução do procedimento por parte dos diferentes estudantes que se colocam na função de experimentador, da topografia das suas verbalizações, de possíveis imprecisões de registro, enfim, de fatores concernentes a controle experimental.
O objetivo do presente trabalho foi dar continuidade ao estudo experimental do comportamento verbal, na linha dos trabalhos desenvolvidos por Taffel (1955) e Matos et al. (1995), investigando os efeitos de conseqüências diferenciais aplicadas ao uso de pronomes na construção de frases, ainda dentro do contexto de uma atividade didática no laboratório de graduação em Psicologia. Procurando avançar na identificação e compreensão do controle exercido pelas conseqüências sobre o comportamento verbal, o presente estudo investigou os efeitos de submeter o uso de pronomes a diferentes contingências de reforçamento, positivo e negativo (v. Catania, 1998; Keller \& Schoenfeld, 1950; Skinner, 1938, para definição e análise dessas contingências).

Para produzir condições de reduzir a variabilidade encontrada em Matos et al. (1995), mantendo e otimizando a realização desse experimento como uma prática de laboratório, o presente trabalho empregou recursos informatizados de procedimento: o aplicativo de computador Verbal 1.51, desenvolvido por Tomanari, Matos, Pavão e Benassi (1999) [posteriormente atualizado nas versões 1.6 (2001), 1.62 (2002) e, atualmente, 2.51 (2005)].

\section{Método}

\section{Participantes}

Foram sujeitos deste estudo 53 estudantes universitários calouros do curso de Psicologia da Faculdade Ruy Barbosa (Salvador, BA), para os quais esse experimento constituiu parte de suas atividades didáticas no Laboratório de Análise Experimental do Comportamento. Os participantes compuseram dois grandes grupos em função da aplicação de dois diferentes pares de contingências ( $v$. descrição detalhada a seguir). Para cada um dos grupos, os sujeitos foram subagrupados em função do pronome selecionado para reforçamento ("Nós" ou "Ele(a)", cf. descrito no procedimento adiante). O número de sujeitos em cada um dos quatro grupos encontra-se disposto no Tabela 1.

\section{Equipamentos e materiais}

As contingências experimentais foram controladas e as respostas dos participantes registradas pelo 
Tabela 1. Grupos experimentais com indicação do pronome selecionado para reforçamento diferencial e conseqüências programadas.

\begin{tabular}{|c|c|c|c|c|c|}
\hline \multirow{2}{*}{ Grupo } & \multirow{2}{*}{ Pronome selecionado } & \multirow{2}{*}{ Denominação } & \multirow{2}{*}{ Sujeitos (n) } & \multicolumn{2}{|c|}{ Conseqüências programadas } \\
\hline & & & & Pronome selecionado & Outros pronomes \\
\hline \multirow[t]{2}{*}{ Reforçamento Positivo } & "Ele(a)" & ele(a)-Pos. & 14 & +10 & - \\
\hline & "Nós" & nós-Pos. & 13 & +10 & - \\
\hline \multirow[t]{2}{*}{ Reforçamento Negativo } & "Ele(a)" & ele(a)-Neg. & 12 & 0 & -10 \\
\hline & "Nós" & nós-Neg. & 14 & 0 & -10 \\
\hline
\end{tabular}

aplicativo de computador Verbal 1.6, versão de 2001 (Tomanari et al., 2003), devidamente instalado em microcomputadores tipo IBM-PC equipados com monitores coloridos de 14 polegadas e mouse. $\mathrm{O}$ programa de computador Verbal 1.6 foi configurado para executar as contingências programadas segundo o procedimento abaixo.

\section{Procedimentos}

Por meio do aplicativo de computador Verbal 1.6, o procedimento submeteu os participantes à tarefa de construção de frases. Para isso, 72 verbos, na forma infinitiva, foram apresentados na parte centro-superior do monitor de vídeo, seqüencialmente. Tratavam-se de verbos regulares, concretos e abstratos, da primeira e da segunda conjugação. Esses verbos, escolhidos entre os usados na vida cotidiana, foram originalmente propostos por Matos et al. (1995), e encontram-se listados em Matos e Tomanari (2002, p. 236).

A apresentação dos verbos era acompanhada, simultaneamente, por três menus drop-down alinhados horizontalmente no centro do monitor. Para construir uma frase, o participante devia selecionar, consecutivamente, uma dentre seis opções disponíveis em três menus (Figura 1):

1) Pronome: O participante escolhia, no primeiro menu, um dentre os seis pronomes do caso reto - "Eu", "Tu", "Ele(a),", "Nós", ,'Vós,", "Eles(as)”- para iniciar a frase.

2) Verbo: O segundo menu apresentava o verbo corrente conjugado em seis diferentes tempos verbais presente, pretérito perfeito, pretérito imperfeito, pretérito mais que perfeito, futuro do presente e futuro do pretérito -, cada qual devidamente conjugado de acordo com o pronome selecionado pelo participante no menu

208 anterior.

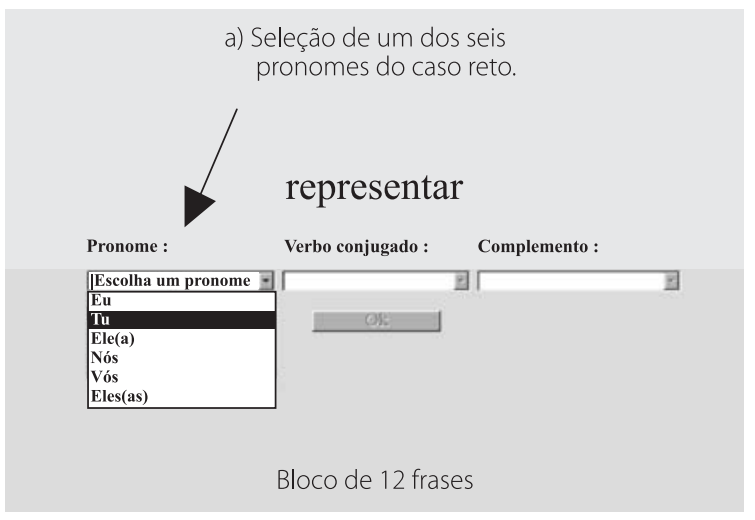

b) Seleção de um verbo dentre seis diferentes tempos verbais apresentados.
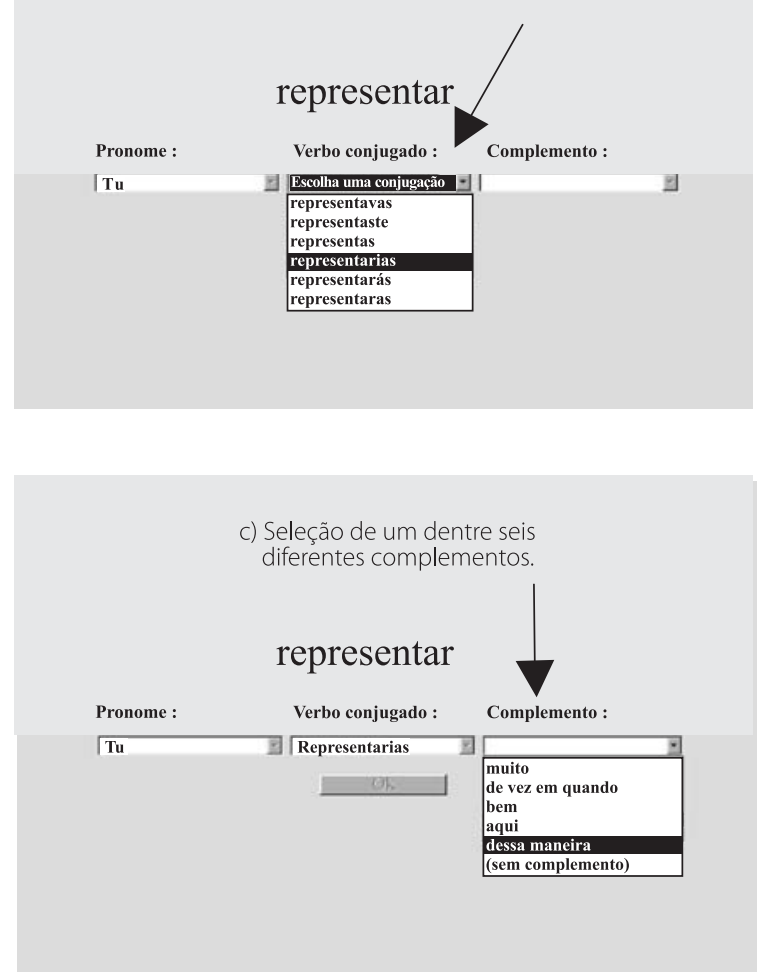

Figura 1. Representação das telas do computador tal como visualizadas pelos participantes na seqüência de construção de uma frase. 
3) Complemento: Para finalizar a frase, o participante dispunha, no terceiro menu, de cinco opções de complementos verbais, entre diferentes advérbios e locuções adverbiais, além da opção sempre disponível de não utilizar um complemento (opção "sem complemento"), no caso de verbos intransitivos, por exemplo.

Os menus eram ativados por um único clicar do mouse sobre cada um deles e, havendo a seleção de um dos seus itens, esse menu era desativado e o seguinte imediatamente ativado. Assim, uma vez feita uma seleção, não era possível alterá-la posteriormente. Após a seleção final no menu de complementos, a conclusão da frase era confirmada acionando-se com o mouse o botão contendo a palavra "OK", situado na parte inferior da tela. Imediatamente após o encerramento da frase, seguiram-se diferentes conseqüências em função do pronome selecionado pelo participante e da contingência de reforçamento em vigor (ver detalhamento adiante).

Entre o encerramento de uma frase e o início da seguinte havia sempre um intervalo de um segundo e meio durante o qual a tela permanecia completamente branca e inativa (intervalo entre tentativas). A cada frase, uma nova seqüência dos elementos que compunham os menus era sorteada, garantindo-se a eqüiprobabilidade de repetições de um mesmo pronome ou tempo verbal em uma mesma posição na lista.

Para todos os participantes, a sessão experimental consistiu da apresentação de doze verbos iniciais na ausência de reforçamento (linha de base), seguida pela apresentação de 60 verbos em que se aplicaram conseqüências diferenciais.

Durante a fase de linha de base, independentemente do pronome selecionado pelo participante, o computador não liberava, ao final da frase construída pelo participante, qualquer conseqüência diferencial.

Durante a condição experimental, dois diferentes pares de contingências foram aplicados, em dois diferentes grupos de sujeitos, à utilização do pronome "Nós", alternativamente à utilização de qualquer um dos outros cinco pronomes.

Em um dos pares de contingências, o início da $13^{\text {a }}$ tentativa era acompanhado pelo aparecimento, na tela do computador, do contador de pontos marcando zero. A partir de então, e até o final do experimento, o uso do pronome "Nós" era seguido pelo acréscimo de dez pontos no contador; nesse caso, aparecia " +10 " na tela, antes do início do intervalo entre tentativas. Alternativamente, o uso de qualquer um dos demais cinco pronomes não alterava a quantidade de pontos; nesse caso, dava-se início imediato ao intervalo entre tentativas. Programaram-se, assim, contingências de reforçamento positivo do uso do pronome "Nós".

No outro par de contingências, o início da 13a tentativa era acompanhado pelo contador marcando 600 pontos. A partir de então, e até o final do experimento, o uso do pronome "Nós" não alterava a quantidade de pontos presentes no contador; nesse caso, aparecia "0" ponto na tela imediatamente antes do início do intervalo entre tentativas. O uso de qualquer um dos demais cinco pronomes era seguido pela subtração de dez pontos; nesse caso, aparecia "-10" na tela do computador antes do início do intervalo entre tentativas. Programaram-se, assim, contingências de reforçamento negativo do uso do pronome "Nós".

Para fins de controle experimental, ambas as contingências descritas acima foram aplicadas ao pronome "Ele(a)" no lugar do pronome "Nós" em dois diferentes subgrupos de sujeitos.

A Tabela 1 resume as contingências utilizadas com a seleção do pronome para reforçamento diferencial, "Nós" e "Ele(a)", e apresenta o número de sujeitos expostos a cada condição experimental.

A execução do presente estudo deu-se coletivamente, em duas sessões consecutivas, uma com 26 e outra com 27 alunos, cada um deles sentado à frente de um dos computadores da sala de informática da Faculdade Ruy Barbosa. As contingências foram configuradas pelos experimentadores antes do acesso dos participantes à sala de coleta, respeitando-se uma distribuição eqüitativa dos quatro diferentes grupos experimentais nas duas sessões de coleta. A sessão teve início com a instrução do experimentador para que os participantes acionassem o mouse, o que fazia aparecer a seguinte mensagem na tela do computador, que era lida em voz alta pelo experimentador (Tabela 2). 
Tabela 2. Instruções do experimentador.

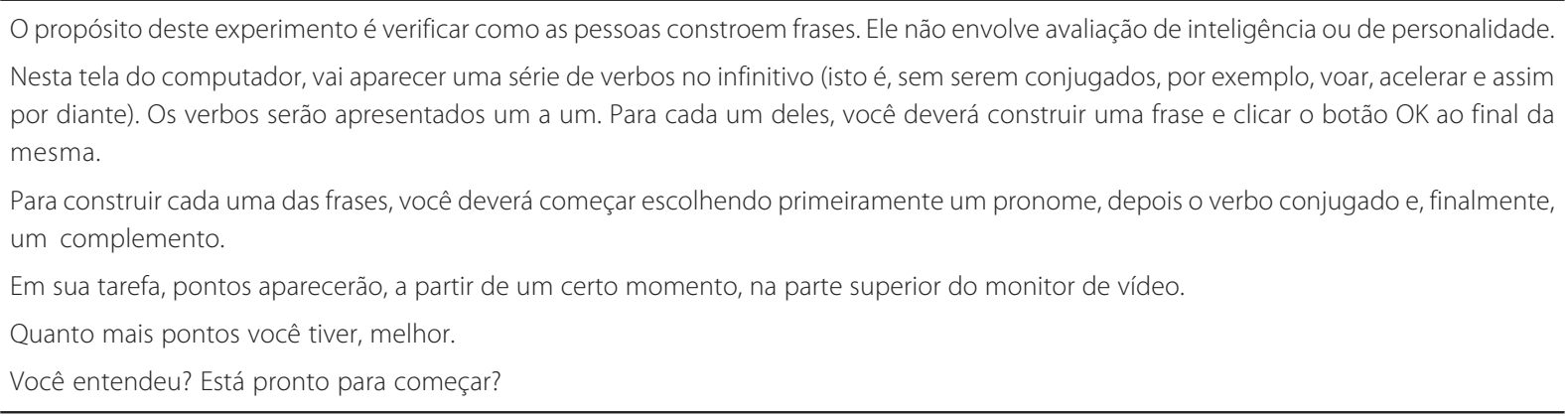

Se, após lidas as instruções, algum participante solicitasse esclarecimentos, o experimentador limitava-se a ler as instruções novamente, sem fazer qualquer outro comentário. Após o participante ter construído as 72 frases, a sessão era finalizada. O computador emitia a seguinte mensagem, agradecendo ao participante: "Você chegou ao final da sessão. Muito obrigado pela sua participação. O experimentador está à sua disposição para lhe fornecer esclarecimentos e tirar qualquer dúvida sobre este estudo. Por favor, mantenha-se em silêncio, aguardando até que todos os seus colegas encerrem o trabalho".

Por esse experimento fazer parte integrante das atividades de laboratório da disciplina Psicologia Experimental, os docentes responsáveis discutiram com os alunos, posteriormente, os objetivos e o método do experimento. Os dados foram impressos e distribuídos para serem tratados, analisados e discutidos em sala de aula.

\section{Resultados}

É um dos pontos centrais do presente estudo avaliar os efeitos de dois pares diferentes de contingências que produziriam, ambas, um aumento na freqüência de utilização de um único e determinado pronome - no caso, "Nós" ou “Ele(a)". Os sujeitos podiam ganhar pontos ao utilizar o pronome selecionado pelo experimentador, ou mantê-los inalterados, ao utilizar qualquer outro pronome (contingência programada de reforçamento positivo). Na outra condição, os sujeitos podiam manter os seus pontos inalterados, ao utilizar o pronome selecionado pelo experimentador, ou perder pontos, ao utilizar qualquer outro pronome (contin-

210 gência programada de reforçamento negativo).
A Figura 2 busca comparar, inicialmente, ambos os pares programados de contingências (reforçamento positivo, colunas cinzas; reforçamento negativo, colunas pretas) a partir de suas respectivas linhas de base (colunas hachuradas claras e escuras, respectivamente, à esquerda da linha horizontal), independentemente do pronome selecionado pelo experimentador para reforçamento.

Os dados mostrados na Figura 2 revelam que, na linha de base, os sujeitos, em média, utilizaram os pronomes que seriam posteriormente reforçados, "Nós" e "Ele(a)" em torno de duas vezes. Ou seja, em 2/12 (ou 1/6) das oportunidades, o que corresponde exatamente a uma distribuição equiprovável de qualquer pronome entre os seis disponíveis.

Na seqüência das frases construídas sob condições de reforçamento, o uso do pronome selecionado aumentou gradual e sistematicamente. Até o bloco 2 (o

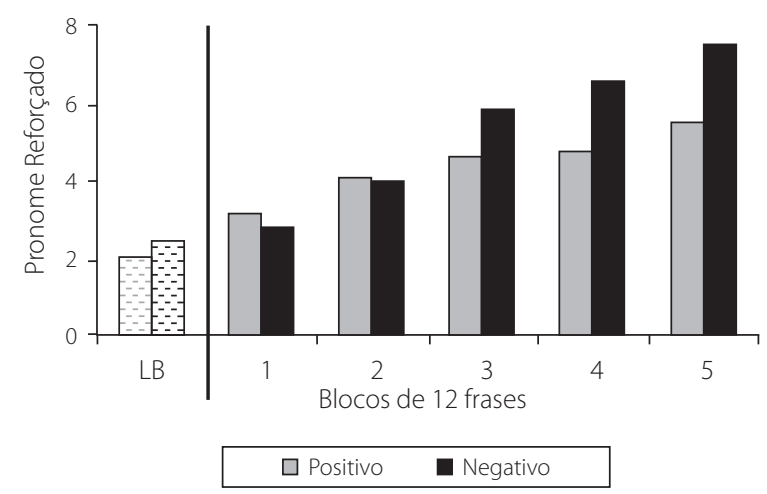

Figura 2. Freqüência média de utilização do pronome selecionado para reforçamento sob as contingências de reforçamento positivo e negativo, a partir de suas respectivas linhas de base, no decorrer de cinco blocos consecutivos de 12 frases cada um. 
que corresponde a 24 frases), os efeitos dos reforçamentos positivo e negativo sobre a freqüência do pronome selecionado são praticamente indistintos. A partir do bloco 3 até o bloco 5, entretanto, as contingências de reforçamento negativo foram acompanhadas de freqüências claramente maiores no uso do pronome reforçado.

A Figura 3 detalha os dados anteriores e distingue as freqüências de utilização dos pronomes "Nós" (quadrados) e "Ele(a)" (círculos) nas 12 primeiras frases construídas em linha de base (pontos à esquerda da linha horizontal), bem como nos cinco blocos consecutivos de 12 frases, às quais se aplicaram conseqüências diferenciais. Na figura, os símbolos cinza e preto referem-se, respectivamente, às contingências de reforçamento positivo e negativo. Conforme se pode verificar, na linha de base (bloco LB), o uso dos pronomes "Ele(a)" e "Nós" ocorreu em freqüências bastante próximas entre si para todos os grupos de sujeitos. No decorrer da fase de reforçamento (blocos 1 e 5), verifica-se um aumento da freqüência de uso de ambos os pronomes. Até o bloco 2, ambos são utilizados em freqüências próximas. A partir do bloco 3, entretanto, tanto o pronome"Nós" quanto o pronome "Ele(a)" passaram a ser utilizados em freqüências mais elevadas sob as contingências de reforçamento negativo. Interessante-mente, entretanto, em cada uma dessas contingências, o uso do pronome"Nós" foi sempre mais utilizado do que o pronome "Ele(a)".

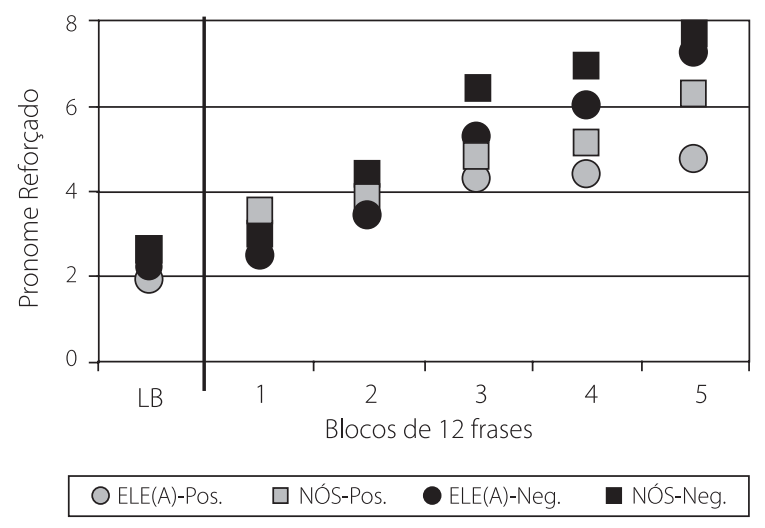

Figura 3. Freqüência média de utilização dos pronomes "Nós" e "Ele(a)" sob as contingências de reforçamento positivo e negativo, a partir da linha de base, no decorrer de cinco blocos consecutivos de 12 frases cada um.
A Figura 4, ao analisar a utilização do pronome reforçado à luz dos outros cinco pronomes, tanto na linha de base (linhas tracejadas) quanto sob reforçamento (linhas contínuas), mostra a distribuição de freqüência de uso de cada um dos seis pronomes - "Eu", “Tu","Ele(a)","Nós","'Vós,,"Eles(as") - para cada contingência de reforçamento (positivo e negativo), e para cada pronome selecionado: "Nós"e "Ele(a)".

Os dados apresentados em todos os gráficos da Figura 4 revelam que a distribuição do uso dos pronomes na linha de base, ou seja, na ausência de reforçamento diferencial, é bastante sistemática entre os quatro grupos de sujeitos. Em termos de freqüência, o pronome "Eu" foi sempre mais utilizado do que os demais, seguido por"Nós", "Ele(a)"e"Eles(as)"e, finalmente, por "Tu"e "Vós". Tomando-se as doze últimas frases elaboradas na fase de reforçamento, observou-se o aumento significativo na freqüência de uso do pronome selecionado, "Nós" ou "Ele(a)", condizentemente com os dados mostrados na Figura 3 (bloco 5). Além desse fato, entretanto, pode-se verificar que a distribuição de uso dos pronomes, ao final da fase de reforçamento, tende a se manter conforme descrito para a linha de base. Ou seja, para os sujeitos cujo pronome selecionado para reforçamento era "Nós", a distribuição de freqüência seguia, aproximadamente, esta ordem decrescente de uso: "Nós", "Eu,, "Ele(a)" e "Eles(as)", "Tu" e "Vós". Para os sujeitos cujo pronome selecionado para reforçamento era "Ele(a)", a distribuição de freqüência foi aproximadamente a seguinte: "Ele(a), "Eu", "Nós" ou "Eles(as)", "Tu" e "Vós".

\section{Discussão}

Este trabalho buscou investigar os efeitos da aplicação de conseqüências diferenciais ao uso de pronomes na construção de frases. Especificamente, dois pares de conseqüências diferenciais foram utilizados, de modo que ambos levariam ao aumento no uso de um determinado pronome previamente selecionado pelo experimentador, no caso, "Nós" ou "Ele(a)", em diferentes grupos de sujeitos. Em um par de conseqüências, aplicado a um dos grupos, o uso do pronome selecionado para reforçamento era seguido pelo ganho de pontos, enquanto o uso de qualquer outro os mantinha constantes. No outro par de contingências, 


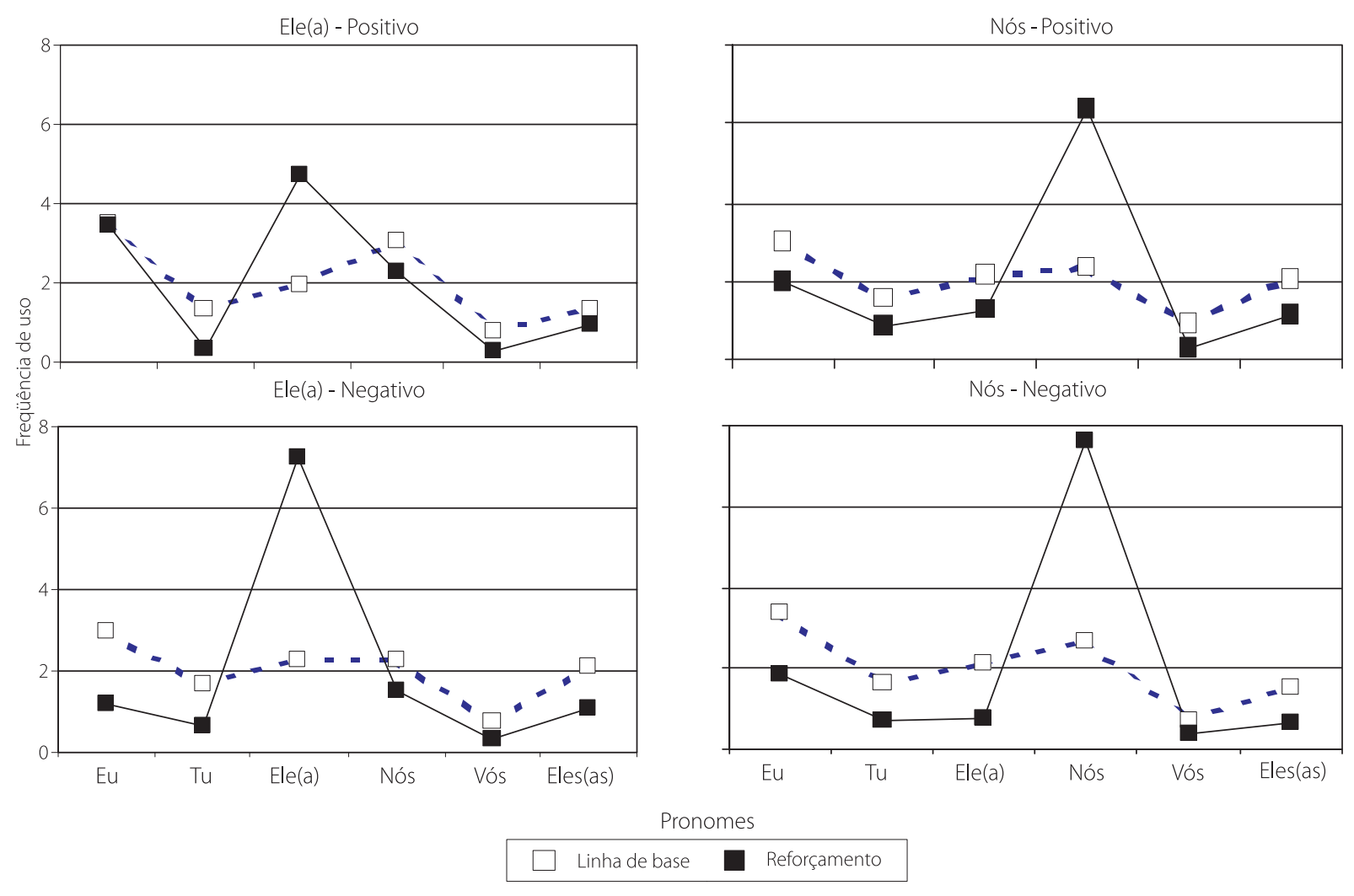

Figura 4. Distribuição da freqüência média de uso de cada um dos seis pronomes nas 12 frases construídas em linha de base e nas 12 últimas frases construídas ao final da fase de reforçamento, sob reforçamento positivo e negativo, para cada pronome selecionado, nós e ele(a).

aplicado a um outro grupo de sujeitos, o uso do pronome selecionado para reforçamento mantinha os pontos constantes enquanto o uso de qualquer outro era seguido pela perda dos mesmos.

Neste trabalho, perguntamos: como poderiam ser comparados os diferentes pares de contingências, que envolveriam diferentes processos comportamentais, reforçamento positivo e negativo, no que diz respeito aos efeitos que produziriam sobre o comportamento humano, em uma de suas formas particulares, ou seja, sobre o comportamento verbal?

Nesse tocante, os dados médios dos grupos de sujeitos submetidos a ambos os pares de contingências revelaram que a freqüência de uso do pronome selecionado para reforçamento foi, inicialmente, semelhante entre si. Entretanto, à medida que a exposição às contingências prosseguia, destacava-se o aumento no uso do pronome reforçado por parte dos sujeitos submetidos à condição programada de reforçamento negativo

212 comparados aos sujeitos submetidos à condição programada de reforçamento positivo. Em termos da freqüência de resposta, portanto, o processo de reforçamento negativo foi acompanhado de um fortalecimento mais acentuado na escolha do pronome selecionado do que o processo de reforçamento positivo.

Interessantemente, as diferenças observadas em ambos os grupos relacionaram-se de alguma forma ao pronome selecionado para reforçamento. O pronome "Nós" foi mais empregado do que "Ele(a)", tanto sob reforçamento negativo quanto sob reforçamento positivo. Possivelmente, esse dado esteja atrelado à demonstração de hierarquia no uso dos pronomes (Matos et al., 1995). Conforme se verificou em linha de base, o uso dos pronomes seguia padrões aparentemente sistemáticos (Figura 4). Por exemplo, reproduzindo-se os achados de Matos et al. (1995), o pronome "Eu" era quase sempre e isoladamente o mais utilizado, enquanto "Tu" " "Vós" tendiam a ser os menos empregados. 
Muito provavelmente, fatores culturais pré-experimentais exerceram papéis importantes nessa utilização basal e, até mesmo por essa razão, os pronomes selecionados para reforçamento nesse experimento - "Nós" e"Ele(a)"- foram determinados em função do fato de terem apresentado, em estudos anteriores, freqüências intermediárias de uso. No entanto, o curioso é notar que "Nós" e "Ele(a)", ao longo do processo de reforçamento, passaram a se diferenciar sistematicamente entre si, relevando diferentes efeitos do reforçamento positivo e negativo sobre cada um deles (Figura 3).

Segundo Critchfield e Magoon (2001), são relativamente escassos na literatura especializada resultados consistentes e sistemáticos oriundos de pesquisas envolvendo participantes humanos submetidos a contingências comparáveis de reforçamento positivo e negativo.

Interessados nos efeitos de "perdas" e "ganhos" de pontos, esses autores levantam o que chamam de "hipótese do impacto diferencial", que se refere ao fato de que determinadas perdas podem exercer maior impacto sobre o comportamento do que ganhos de igual valor. Para esses autores, a melhor alternativa para se elucidar a questão são os experimentos que utilizam humanos como sujeitos, pois a maioria dos experimentos com animais emprega conseqüências reforçadoras (por exemplo, comida) e aversivas (por exemplo, choques) de naturezas diferentes e, por esse motivo, podem não ser comparáveis em uma mesma escala de medida ou podem requerer procedimentos especiais para isso. Nesse sentido, consideramos que o presente estudo, por meio do comportamento humano de construir frases e utilizando-se pontos como reforçadores, configurou um procedimento adequado metodologicamente e aceitável eticamente para estudar contingências de reforçamento positivo e negativo.

Os presentes dados indicam que o processo de reforçamento negativo, comparativamente ao positivo, foi acompanhado de um fortalecimento mais preponderante do pronome selecionado. Entretanto, há uma característica do procedimento que pode se correlacionar com esses resultados. Apesar de a manutenção de pontos ter sido uma alternativa presente tanto na contingência de reforçamento positivo quanto na contingência de reforçamento negativo, havia uma diferença entre essas duas contingências. Na primeira, a manutenção de pontos dava-se pela apresentação do intervalo entre tentativas, durante a qual a tela do computador permanecia completamente branca ("- -", na Tabela 1). Na segunda, diferentemente, era apresentado o número "zero" na tela do computador, imediatamente antes do intervalo entre tentativas (" 0 ", na Tabela 1). Durante o processo de reforçamento positivo, a ausência de uma conseqüência explícita associada ao uso de um pronome diferente daquele selecionado para reforçamento pode ter desempenhado um papel relevante para os dados obtidos. Durante a linha de base, não se apresentou qualquer conseqüência diferencial, de modo que a finalização das frases era seguida pela tela em branco do computador.

Dessa forma, a condição de reforçamento positivo compartilhava semelhanças com a linha de base que a condição de reforçamento negativo não compartilhava. Por exemplo, a partir da 13a frase (início da fase de reforçamento), um sujeito que estivesse na condição de reforçamento positivo, e não utilizasse o pronome empregado para reforçamento, não teria qualquer sinalização de que as condições experimentais haviam se alterado. Algo semelhante não ocorria para os sujeitos sob reforçamento negativo que, ao deixar a linha de base, notavam imediatamente " 0 " ou "-10" ao finalizar as suas frases. Essa diferença, entretanto, não parece suficiente para explicar os diferentes desempenhos médios dos sujeitos sob reforçamento positivo e negativo, que passaram a se diferenciar a partir do terceiro bloco de frases construídas e, portanto, mantiveram-se semelhantes justamente nos primeiros blocos, quando se esperariam os efeitos mais acentuados da apresentação ou não do "0".

Em estudos futuros, portanto, há de se considerar a equalização dessa variável de modo a aprimorar o controle experimental e, assim, acrescentar novos achados à presente proposta metodológica para o estudo do comportamento humano sob contingências de reforçamento. Seria interessante, por exemplo, analisar os processos de reforçamento positivo e negativo sob novos pares de contingências. Dentre eles, poderiam ser comparadas condições de reforçamento 
em que sempre se ganham ou sempre se perdem pontos, porém em diferentes magnitudes. Nessa linha, por exemplo, o uso do pronome selecionado seria seguido pelo ganho de dez pontos, enquanto o uso de qualquer outro pronome seria seguido pelo ganho de um ponto. Ou, alternativamente, o uso do pronome selecionado seria seguido pela perda de um ponto, enquanto o uso de qualquer outro pronome seria seguido pela perda de dez pontos.

Este estudo foi realizado no contexto de uma atividade didática no laboratório de Análise Experimental do Comportamento. Por essa razão, procurou-se fazer com que os alunos fossem sujeitos experimentais e utilizassem os seus próprios dados para tratamento, análise e discussão dos resultados e, com isso, passassem pelas etapas concretas de se fazer uma pesquisa. Dessa forma, a coleta de dados precisou se adequar à situação de ensino e, por isso, foi necessário concluí-la em apenas uma única sessão que fosse longa o suficiente para permitir a demonstração dos efeitos do reforçamento e curta o bastante para manter o engajamento dos sujeitos na tarefa.

No planejamento desse experimento, levadas essas questões em consideração, optou-se pelo delineamento de grupo, no qual diferentes sujeitos foram submetidos a diferentes condições experimentais. Assim, os dados do presente estudo servem aos propósitos didáticos e propiciam uma primeira abordagem dos efeitos de contingências de reforçamento positivo e negativo sobre o comportamento humano. Para continuidade dessa linha de investigação, um próximo passo seria analisar os processos de reforçamento positivo e negativo como efeito de contingências que são alteradas sistematicamente e aplicadas a um mesmo sujeito ao longo de uma história experimental de aprendizagem.

\section{Referências}

Critchfield, T. S., \& Magoon, M. A. (2001). On the differential impact of positive and negative reinforcement. Experimental Analysis of Human Behavior Bulletin, 19 (1), $16-18$

Greenspoon, J. (1955). The reinforcing effect of two spoken sounds on the frequency of two responses. American Journal of Psychology, 68 (3), 409-416.

Keller, F. S., \& Schoenfeld, W. N. (1950). Principles of psychology. New York: Appleton-Century-Krofts.

Krasner, L. (1958). Studies of the conditioning of verbal behavior. Psychological Bulletin, 55 (3), 148-170.

Matos, M. A., Cirino, S., Passos, M. L., Damiani, K., \& Frochtengarten, F. (1995). O comportamento verbal como operante: uma experiência didática. Resumos da XXV Reunião Anual de Psicologia (p.461). Ribeirão Preto.

Matos, M. A., \& Tomanari, G. Y. (2002). A Análise do Comportamento no laboratório didático. São Paulo: Manole.

Passos, M. L. R. F. (2004). Bloomfield e Skinner: a língua e comportamento verbal. Rio de Janeiro: Nau Editora.

Skinner, B. F. (1938). The behavior of organisms. New York: Appleton Century-Crofts.

Skinner, B. F. (1957). Verbal Behavior. New York: Appleton-Century-Crofts.

Taffell, C. (1955). Anxiety and the conditioning of verbal behavior. Journal of Abnormal and Social Psychology, 51 (3), 496-501.

Tomanari, G. Y., Matos, M. A., Pavão, I., \& Benassi, M. T. (1999). Programa Verbal v. 1.51. Laboratório de Análise Experimental do Comportamento - IPUSP (versão 1.6, de 2001; versão 1.62, de 2002; versão 2.51, de 2005).

Wilson, W. C., \& Verplanck, W. S. (1956). Some observations on the reinforcement of verbal operants. American Journal of Psychology, 69 (3), 448-451.

Recebido em: 2/5/2006

Aprovado em: 27/7/2006 